\title{
AVALIAÇÃO DA FERTILIDADE DOS SOLOS DA REGIÃO PRODUTORA DE ABACAXI DO ESTADO DA PARAÍBA
}

\author{
Lúcia Helena Garófalo Chaves ${ }^{1}$, Ramara Sena de Souza ${ }^{2}$ \\ ${ }^{1}$ Professora Titular Doutora, Departamento de Engenharia Agrícola, Centro de Tecnologia e \\ Recursos Naturais da Universidade Federal de Campina Grande, Campina Grande, PB, \\ Brasil (Ihgarofalo@hotmail.com) \\ ${ }^{2}$ Doutoranda, Departamento de Engenharia Agrícola, Centro de Tecnologia e Recursos \\ Naturais da Universidade Federal de Campina Grande, Campina Grande, PB, Brasil \\ Recebido em: 03/10/2016 - Aprovado em: 21/11/2016 - Publicado em: 05/12/2016 \\ DOI: 10.18677/EnciBio 2016B 011
}

\begin{abstract}
RESUMO
Devido ao elevado grau de exigência do abacaxizeiro, a fertilidade do solo pode ser prejudicada quando os nutrientes não são repostos aos solos. Diante disso, objetivou-se diagnosticar a fertilidade dos solos dos últimos cinco anos da região produtora de abacaxi do Estado da Paraíba. Para isto, os resultados das análises físico-químicas de amostras de solos relacionados à fertilidade, de treze municípios, realizadas no Laboratório de Irrigação e Salinidade da Universidade Federal de Campina Grande, PB, foram classificados de acordo com critérios de fertilidade e avaliados por meio das seguintes medidas descritivas: média, valores máximos e mínimos. A classificação textural, os teores de cálcio, magnésio, potássio e fósforo dos solos da região produtora de abacaxi do Estado da Paraíba, são adequados para a cultura. Entretanto, para evitar o esgotamento dos solos desta região, cultivada por várias décadas, é necessário a adição de matéria orgânica e de fertilizantes, principalmente, potássio e fósforo, proporcionando bons rendimentos.
\end{abstract}

PALAVRAS-CHAVE: atributos químicos, Ananas comosus L, interpretação dos atributos químicos, textura do solo

\section{SOIL FERTILITY OF REGION PRODUCING PINEAPPLE OF PARAIBA STATE}

\begin{abstract}
Due to the high demands of pineapple, soil fertility may be impaired when the nutrients are not replenished soils. Thus, the aim of this study was to diagnose soil fertility of the last five years of region producing pineapple of Paraiba State. For this, the results of physico-chemical analysis of soil samples related to fertility, from thirteen municipalities, carried out in Irrigation and Salinity Laboratory of the Federal University of Campina Grande, PB, were classified according to fertility criteria and evaluated by the following descriptive statistics: mean, maximum and minimum values. Textural classification, levels of calcium, magnesium, potassium and phosphorus and the reaction of the producer of pineapple Paraiba State region soils are suitable for that crop. However, to avoid depletion of this region soil, cultivated for several decades, the addition of organic matter is necessary and fertilizers, mainly potassium and phosphorus, providing good yields.
\end{abstract}

KEYWORDS: chemical attributes, soil texture, interpretation of chemical attributes, Ananas comosus $L$. 


\section{INTRODUCAO}

$\mathrm{O}$ abacaxizeiro (Ananas comosus L. Merril), símbolo de regiões tropicais e subtropicais, é o membro da família Bromeliaceae. Trata-se de uma espécie importante economicamente, tendo grande aceitação em todo o mundo tanto na forma natural, quanto industrializado, agradando aos olhos, ao paladar e ao olfato (CRESTANI et al., 2010).

Segundo a maioria dos naturalistas e historiadores, o abacaxi é originário da América tropical e subtropical e, muito provavelmente, do Brasil (MEDINA et al., 1978). Há indícios que sua domesticação ocorreu muitos séculos anteriores à era pré-colombiana (SIMÃO, 1998). A dispersão pelos vários países americanos iniciouse com o intercâmbio entre tribos; contudo, com o descobrimento da América, se tornou conhecido mundialmente, quando foi levado para a Europa, Ásia e África e se disseminou por vários países rapidamente (CTENAS \& QUAST, 2000).

Atualmente, o abacaxi é extensivamente produzido em todos os países tropicais, sendo o Brasil o maior produtor, pois são encontradas excelentes condições para o desenvolvimento, de forma que é cultivado em quase todos os Estados (CRESTANI et al., 2010; IBGE, 2015), tornando-se, portanto, a terceira fruteira tropical mais plantada no país.Conforme os dados publicados no IBGE (2015), no período da safra 2015, na área colhida de 66.968 hectares, foram produzidos 1.773.270 mil frutos, apresentando um rendimento médio de 26.479 frutos por hectare. A Região Nordeste é a maior produtora de abacaxi do País, 23.151 hectares, produzindo 650.135 mil frutos, respondendo por $37,1 \%$ do total da área a ser colhida no Brasil. Em área, o estado do Pará é o maior plantador de abacaxi (11.303 ha), seguido pelo estado da Paraíba (9.341 ha) com produções de 353.721 e 280.042 mil frutos, respectivamente.

No estado da Paraíba são vários os municípios produtores de abacaxi. Aqueles que possuem as maiores áreas de produção são Itapororoca (2.520 ha), Araçagi (2.200 ha), Santa Rita (1.700 ha), Pedra de Fogo (1.500 ha), Cuité de Mamanguape (500 ha), Lagoa de Dentro (420 ha) e Sapé (230 ha). Apesar disso, outros municípios próximos a região de Santa Rita, também produzem abacaxi como produto agrícola principal na economia dos mesmos.

Devido ao elevado grau de exigência do abacaxizeiro, para todos os plantios é necessário aplicar fertilizante nos solos.. Como os solos são sistemas dinâmicos e abertos, em constantes modificações, a aplicação destes fertilizantes faz com as propriedades químicas e físicas dos solos variem, e tal fator pode influenciar diretamente na fertilidade dos solos (VITTI, 1987). Diante disso, objetivou-se diagnosticar a fertilidade dos solos dos últimos cinco anos da região produtora de abacaxi do Estado da Paraíba.

\section{MATERIAL E MÉTODOS}

A partir dos resultados das análises físico-químicas das amostras de solos, realizadas ao logo destes últimos cinco anos no Laboratório de Irrigação e Salinidade da Universidade Federal de Campina Grande, PB, foram selecionados aqueles relacionados com as áreas produtoras de abacaxi, variedade Pérola, para ser avaliada a fertilidade destas áreas.

As amostras de solos destas áreas provenientes dos municípios Araçagi, Capim, Conde. Cruz do Espírito Santo, Duas Estradas, Itapororoca, Lagoa de Dentro, Mari, Rio Tinto, Santa Rita, Sapé, Sertãozinho e Sobrado (Figura 1), trazidas pelos agricultores, foram secas ao ar a sombra, peneiradas com malha de $2 \mathrm{~mm}$ de 
diâmetro e em seguida caracterizadas física e quimicamente de acordo com metodologia recomendada por EMBRAPA (1997).

\section{ESTADO DA PARAIBA: MUNICIPIOS}

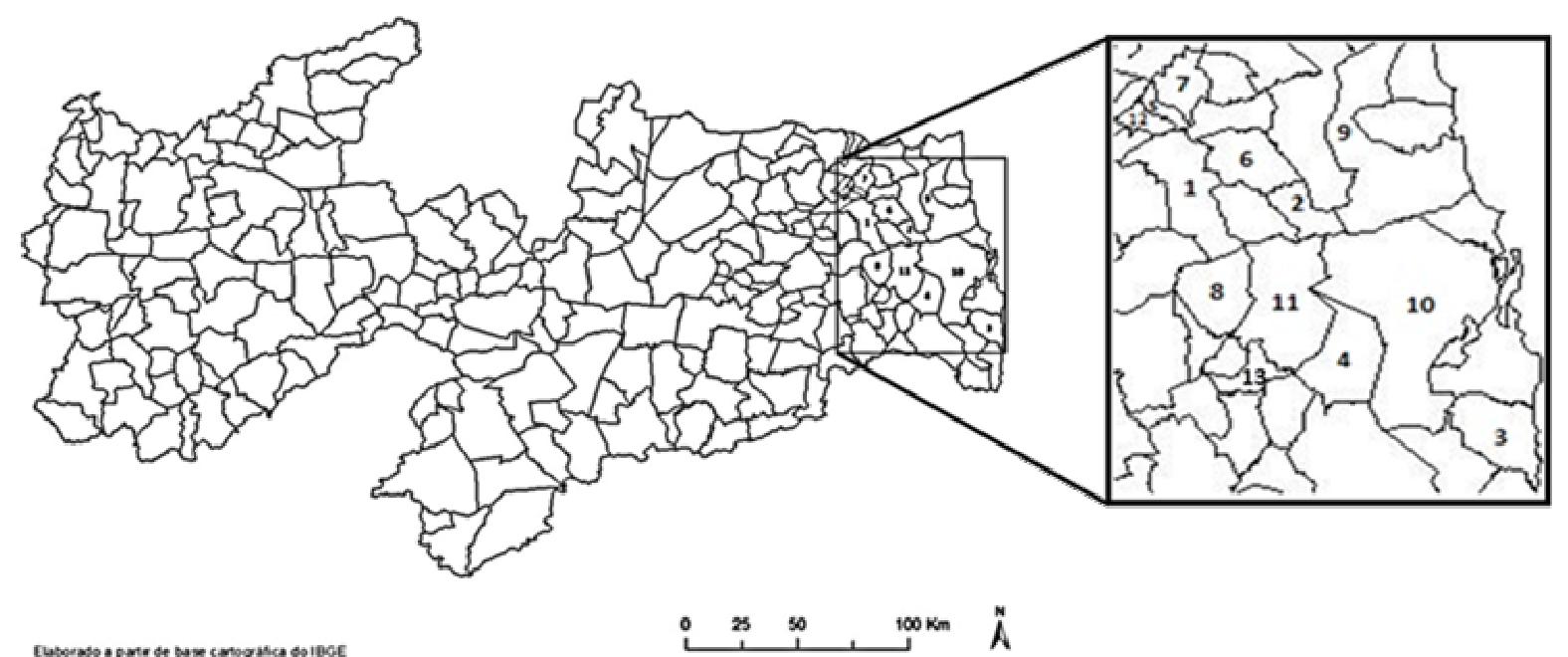

1 - Araçagi; 2 - Capim; 3 - Conde; 4 - Cruz do Espírito Santo; 5 - Duas Estradas; 6 - Itapororoca; 7 - Lagoa de Dentro; 8 - Mari; 9 - Rio Tinto; 10 - Santa Rita; 11 - Sapé; 12 - Sertãozinho; 13 - Sobrado

FIGURA 1. Localização dos municípios produtores de abacaxi.

Os resultados relacionados à fertilidade foram classificados segundo padrões da Comissão de Fertilidade do Solo do Estado do Espírito Santo (DADALTO \& FULLIN, 2001) (Tabela 1). O comportamento das variáveis do solo foi avaliado por meio das seguintes medidas descritivas: média, valores máximos e mínimos.

TABELA 1. Limites de interpretação do nível de fertilidade adotados pelos laboratórios de análise de solo, no Estado do Espírito Santo.

\begin{tabular}{|c|c|c|c|c|c|}
\hline \multirow[b]{2}{*}{ Atributos químicos } & \multicolumn{5}{|c|}{ Classificação e Níveis } \\
\hline & Muito baixo & Baixo & Médio & Alto & Muito Alto \\
\hline $\begin{array}{l}\text { Cálcio }\left(\mathrm{cmol}_{\mathrm{c}} \mathrm{kg}^{-1}\right) \\
\text { Magnésio }\left(\mathrm{cmol}_{\mathrm{c}} \mathrm{kg}^{-1}\right) \\
\text { Potássio }\left(\mathrm{cmol}_{\mathrm{c}} \mathrm{kg}^{-1}\right) \\
\text { Alumínio }\left(\mathrm{cmol}_{\mathrm{C}} \mathrm{kg}^{-1}\right) \\
\text { Acidez Potencial }\left(\mathrm{cmol}_{\mathrm{c}} \mathrm{kg}^{-1}\right) \\
\text { Fósforo Disponível }\left(\mathrm{mg} \mathrm{kg}^{-1}\right)^{\star} \\
\text { Fósforo Disponível }\left(\mathrm{mg} \mathrm{kg}^{-1}\right)^{\star \star} \\
\text { CTC }\left(\mathrm{cmol}_{\mathrm{C}} \mathrm{kg}^{-1}\right)^{1} \\
\text { V }(\%)^{2} \\
\text { Matéria Orgânica }\left(\mathrm{g} \mathrm{kg}^{-1}\right)\end{array}$ & $\leq 25$ & $\begin{array}{l}\leq 1,5 \\
\leq 0,5 \\
\leq 0,07 \\
\leq 0,3 \\
\leq 2,5 \\
\leq 20 \\
\leq 10 \\
\leq 4,5 \\
26-50 \\
\leq 15\end{array}$ & $\begin{array}{c}1,6-4,0 \\
0,6-1,0 \\
0,08-0,15 \\
0,4-1,0 \\
2,6-5,0 \\
21-30 \\
11-20 \\
4,6-10,0 \\
51-70 \\
16-30\end{array}$ & $\begin{array}{l}>4,0 \\
>1,0 \\
>0,15 \\
>1,0 \\
>5,0 \\
>30 \\
>20 \\
>10,0 \\
71-90 \\
>30\end{array}$ & $>90$ \\
\hline & & Acidez & & Neutro & Alcalinidade \\
\hline $\mathrm{pH} \mathrm{H} \mathrm{H}_{2} \mathrm{O}(1: 2.5)$ & $\begin{array}{l}\text { Alta } \\
\leq 5,0\end{array}$ & $\frac{\text { Média }}{5,1-5,9}$ & $\begin{array}{c}\text { Fraca } \\
6,0-6,9\end{array}$ & 7,0 & $\begin{array}{cc}\text { Fraca } & \text { Alta } \\
7,1-7,8 & >7,8\end{array}$ \\
\hline
\end{tabular}

Fonte: DADALTO \& FULLIN (2001); ${ }^{*},{ }^{* *}=$ textura arenosa, textura media, respectivamente; ${ }^{1}=$ capacidade de troca catiônica; ${ }^{2}=$ porcentagem de saturação por bases; ${ }^{3}=$ PIZARRO CABELLO (1985)

\section{RESULTADOS E DISCUSSÃO}

Apesar da grande variação dos valores de cálcio $(\mathrm{Ca})$, nas áreas analisadas predominaram, em média, teores médios do elemento (Tabela 2), sendo que 
somente em Sertãozinho e em Sapé, os teores do Ca foram classificados como baixo $\left(\leq 1,5 \mathrm{cmol}_{\mathrm{C}} \mathrm{kg}^{-1}\right)$ e alto $\left(>4,0 \mathrm{cmol}_{\mathrm{c}} \mathrm{kg}^{-1}\right)$, respectivamente. Considerando que de 2 a $3 \mathrm{cmol}_{\mathrm{c}} \mathrm{kg}^{-1}$ de Ca é adequado para o desenvolvimento das culturas (RAlJ, 1981), pode-se observar que várias áreas agrícolas amostradas apresentam-se como deficientes, ou seja, com teores abaixo desta faixa. Entretanto, a aplicação de calcário, calcítico e/ou dolomítico, nestas áreas com pH baixo, além de neutralizar a acidez dos solos é fonte de $\mathrm{Ca}$, diminuindo assim a deficiência deste elemento.

TABELA 2. Resultados da análise descritiva dos dados de cálcio $(\mathrm{Ca})$, magnésio $(\mathrm{Mg})$, potássio $(\mathrm{K})$, hidrogênio $(\mathrm{H})$, alumínio $(\mathrm{Al}), \mathrm{pH}$, matéria orgânica $(\mathrm{MO})$ e fósforo $(\mathrm{P})$ correspondentes às amostras de solos coletadas em vários municípios.

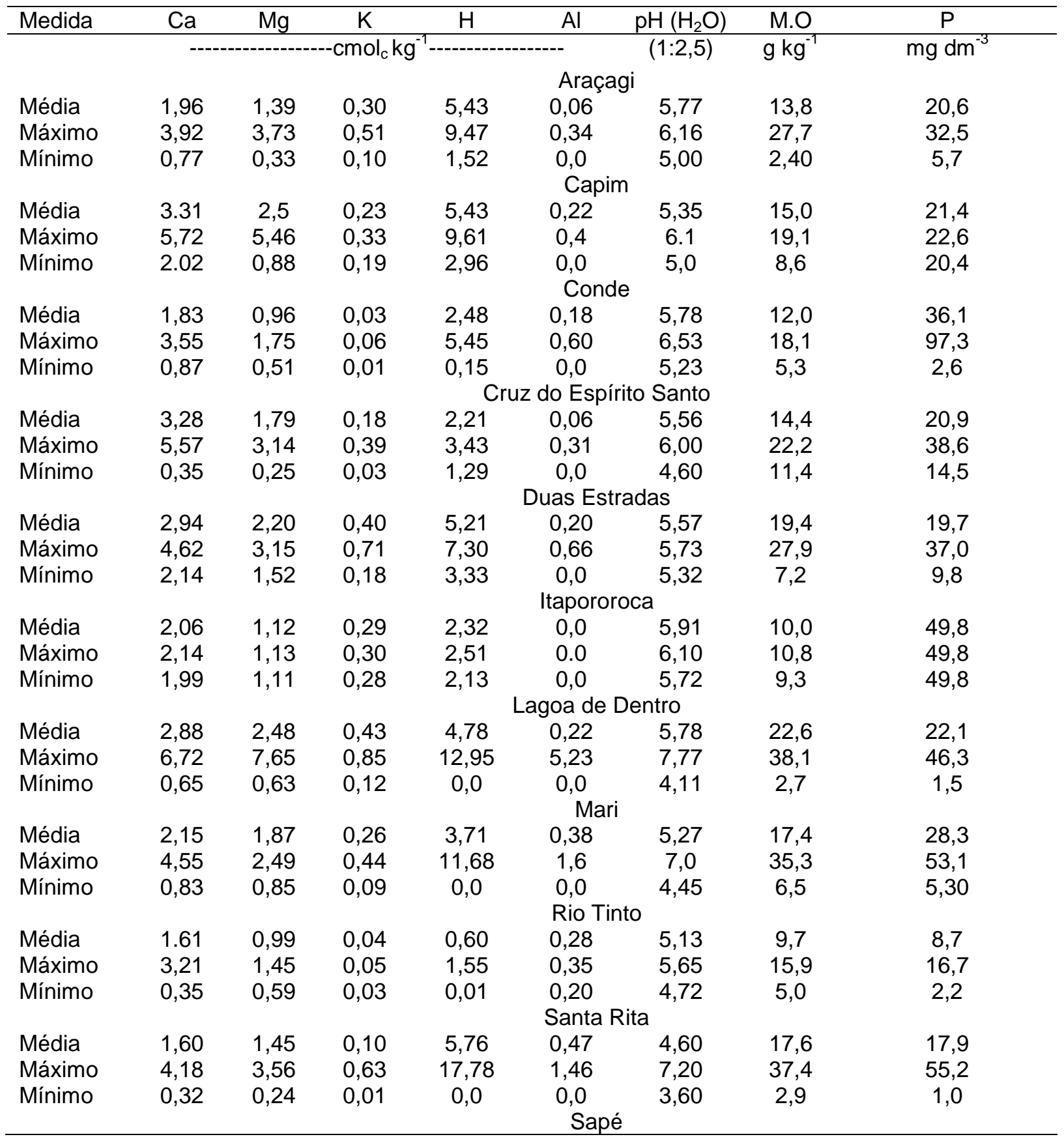




\begin{tabular}{|c|c|c|c|c|c|c|c|c|}
\hline Média & 4,30 & 3,04 & 0,24 & 3,75 & 0,20 & 5,59 & 22,2 & 20,4 \\
\hline Máximo & 11,30 & 7,88 & 0,81 & 10,08 & 0,77 & 7,01 & 35,5 & 53,2 \\
\hline Mínimo & 0,96 & 0,69 & 0,07 & 0,0 & 0,0 & 4,80 & 5,3 & 1,4 \\
\hline & \multicolumn{8}{|c|}{ Sertãozinho } \\
\hline Máximo & 113 & 3.0 & 038 & 300 & 3,31 & 5,63 & 30.0 & 143 \\
\hline Mínimo & 0,94 & 1,42 & 0,20 & 0,60 & $\begin{array}{l}0.0 \\
\text { Sobr }\end{array}$ & 5,40 & 29,5 & 13,3 \\
\hline Média & 2,60 & 1,79 & 0,19 & 1,03 & 0,003 & 6,36 & 10,0 & 43,7 \\
\hline Máximo & 3,53 & 2,73 & 0,28 & 2,89 & 0,03 & 7,16 & 22,2 & 53,3 \\
\hline Mínimo & 1,66 & 1,04 & 0,12 & 0,0 & 0,0 & 5,70 & 2,7 & 11,8 \\
\hline
\end{tabular}

Com exceção dos municípios Rio Tinto e Conde, em todas as outras áreas, os teores médios do magnésio $(\mathrm{Mg})$ foram classificados como alto, ou seja, $>1,0 \mathrm{cmol}_{\mathrm{c}}$ $\mathrm{kg}^{-1}$. No entanto, como o suficiente para a maioria das culturas está em torno de 0,4 $\mathrm{cmol}_{\mathrm{c}} \mathrm{kg}^{-1}$, em nenhuma área houve deficiência de $\mathrm{Mg}$ no solo, principalmente para abacaxi (Tabela 2).

Os teores de potássio $(K)$ nas amostras de solos dos municípios Rio Tinto e Conde, foram classificados como baixo. O teor médio deste elemento no município Santa Rita foi classificado como médio, mas, na maioria das amostras analisadas os teores foram classificados como baixo, variando de 0,01 a $0,07 \mathrm{cmol}_{\mathrm{c}} \mathrm{kg}^{-1}$ (dados não apresentados). Nos demais municípios, os teores médios foram classificados como alto $\left(>0,15 \mathrm{cmol}_{\mathrm{c}} \mathrm{kg}^{-1}\right)$. Ressalta-se que nestes municípios, mesmo sendo adubados em todas as épocas de plantio, os teores de $\mathrm{K}$ continuam sendo classificadas como baixos. Isto ocorre, provavelmente, por causa das grandes perdas do elemento por lixiviação, uma vez que em solos arenosos, como é o caso das áreas de plantio de abacaxi, apresentam baixa capacidade de troca catiônica, e consequentemente, poucos sítios de adsorção do elemento. Além disso, o potássio apresenta apenas uma carga de valência $\left(\mathrm{K}^{+}\right)$, também justifica a pouca adsorção do mesmo nos colóides do solo (ERNANI et al. 2007).

Outro fator que influencia nas perdas de potássio por lixiviação é a fonte de potássio a ser utilizada (YAMADA \& ROBERTS, 2005). Sais de potássio, como por exemplo, sulfato de potássio de alta solubilidade, conferem à solução do solo altos teores de potássio e, com isto, este elemento fica propício a ser lixiviado.

Considerando a classificação do fósforo $(P)$ presente nas amostras arenosas, de modo geral, os teores médios de vários municípios se apresentaram como baixos ( $\leq 20 \mathrm{mg} \mathrm{kg}^{-1}$ ) (sete municípios), médios $\left(21-30 \mathrm{mg} \mathrm{kg}^{-1}\right.$ ) (três municípios) e altos (> $30 \mathrm{mg} \mathrm{kg}^{-1}$ ) (três municípios) (Tabela 2). No entanto, considerando a recomendação de adubação para a cultura do abacaxi, de acordo com CAVALCANTI (1998), os teores de fósforo $<6 ; 6-10$ e $>10 \mathrm{mg} \mathrm{kg}^{-1}$ são classificados como baixo, médio e alto, respectivamente. Interpretando os resultados das amostras de solo analisadas com base nestes níveis, observa-se que em todas estas amostras os teores de fósforo são altos. Assim, recomenda-se menor aplicação de adubo fosfatado no plantio de abacaxi.

Os médios e altos teores, tanto de potássio como de fósforo, encontrados nas amostras dos solos podem ser atribuídos as freqüentes aplicações de fertilizantes ao longo do ano nas áreas de plantio de abacaxi, uma vez que a própria natureza destes solos é pobre destes elementos. No caso do fósforo, por mover-se no solo por difusão, o que the acarreta pouca mobilidade, também contribui para o seu acúmulo no solo. 
Os teores de matéria orgânica (MO), em geral, variaram de baixo (em sete municípios) a médio (seis municípios) (Tabela 2). Considerando que a MO funciona como condicionador de solo, exercendo múltiplos efeitos sobre as propriedades físicas, químicas e biológicas dos solos, fica evidente a necessidade da aplicação de fontes ricas em $\mathrm{MO}$. $\mathrm{O}$ aumento no teor de $\mathrm{MO}$ poderá melhorar a retenção de água nos solos mais arenosos; além disso, favorece a melhoria da fertilidade dos solos, devido a disponibilização de elementos essenciais para as plantas como fósforo, magnésio, cálcio, enxofre e micronutrientes.

Os teores médios de alumínio ( $\mathrm{Al}$ ) predominaram em nível baixo, ou seja, $\leq 0,3$ $\mathrm{cmol}_{\mathrm{C}} \mathrm{kg}^{-1}$. No caso da acidez potencial $(\mathrm{H})$, seis, quatro e três municípios se apresentam com teores baixos $\left(\leq 2,5 \mathrm{cmol}_{\mathrm{C}} \mathrm{kg}^{-1}\right)$, altos $\left(>5,0 \mathrm{cmol}_{\mathrm{C}} \mathrm{kg}^{-1}\right)$ e médios $\left(2,6-5,0 \mathrm{cmol}_{\mathrm{c}} \mathrm{kg}^{-1}\right)$, respectivamente.

A acidez potencial e o teor de alumínio estão relacionados à acidez dos solos. Pode-se observar que somente as amostras de Santa Rita, de acordo com a média do $\mathrm{pH}$, apresentaram acidez alta, ou seja $\mathrm{pH} \leq 5,0$. Nos demais municípios as amostras de solo foram classificadas como acidez média $(\mathrm{pH}=5,1-5,9)$ (Tabela 2). Entretanto, em todas as áreas analisadas, os valores médios de $\mathrm{pH}$ encontraram-se dentro da faixa adequada para a cultura do abacaxi, a qual varia de 4,5 a 5,5. Mesmo assim, é necessário um acompanhamento constante da acidez dos solos, uma vez que é imprescindível mante-la nesta faixa adequada.

As classificações texturais das amostras dos solos das áreas de plantio de abacaxi foram, predominantemente, Areia, Areia Franco e Franco Arenoso, ou seja, as texturas ideais para este plantio. No entanto, solos arenosos como estes, são pobres em nutrientes, por isso, para aumentar a produção dos plantios com fins comerciais e melhorar a qualidade do fruto de abacaxi é importante e obrigatório fazer a adubação, no plantio e/ou na cobertura desta cultura, para fornecer os nutrientes que estes solos não os têm nas quantidades que a planta necessita.

\section{CONCLUSÕES}

A classificação textural, os teores de cálcio, magnésio, potássio e fósforo e a reação dos solos da região produtora de abacaxi do Estado da Paraíba são adequados para a referida cultura. Entretanto, para evitar o esgotamento dos solos desta região, cultivada por várias décadas, é necessário a adição de matéria orgânica e de fertilizantes, principalmente, potássio e fósforo, proporcionando bons rendimentos.

\section{REFERÊNCIAS}

CAVALCANTI, F.J.A. Recomendações de adubação para o estado de Pernambuco (2⿳亠丷⿵冂⿱⺊口灬. Aproximação). Recife: IPA, 1998. 198p.

CRESTANI, M.; BARBIERI, R.L.; HAWERROTH, F.J.; CARVALHO, F.I.F.; OLIVIERA, A.C. Das Américas para o Mundo: origem, domesticação e dispersão do abacaxizeiro. Ciência Rural, v. 40, n. 6, p. 1473-1483, 2010. Disponível por meio de <http://dx.doi.org/10.1590/S0103-84782010000600040>. DOI: 10.1590/S010384782010000600040

CTENAS, M.L.B.; QUAST, D. Abacaxi. Frutas das terras brasileiras. São Paulo: C2, 2000. p.41-45. 
DADALTO, G.G.; FULLIN, E.A. Manual de recomendação de calagem e adubação para o estado do Espírito Santo. 4⿳亠丷a aproximação. Vitória, ES: SEEA/INCAPER, 2001. 266p.

EMBRAPA - EMPRESA BRASILEIRA DE PESQUISA AGROPECUÁRIA. Centro Nacional de Pesquisa de Solos. Manual de métodos de análise do solo. Brasília, 1997. 212p.

ERNANI, P. R.; BAYER, C.; ALMEIDA, J.A.; CASSOL, P.C. Mobilidade vertical de cátions influenciada pelo método de aplicação de cloreto de potássio em solos com carga variável. Revista Brasileira de Ciência do Solo, Viçosa, v. 31, n. 2, p. 393402, 2007. Disponível por meio de < http://dx.doi.org/10.1590/S010006832007000200022 >. DOI: 10.1590/S0100-06832007000200022.

IBGE - Instituto Brasileiro de Geografia e Estatística. Levantamento sistemático da produção agrícola. 2015. Disponível em:

http://www.sidra.ibge.gov.br/bda/agric/default. Acesso em: 26 de julho de 2016.

MEDINA, J.C. A cultura do abacaxi. In: MEDINA, J.C. et al. Frutas tropicais 2. São Paulo: Canton, p.06-68.1978.

PIZARRO CABELLO, F. Drenage agricola y recuperación de suelos salinos. 2. ed. Madrid: Editorial Agrícola Espanhola S. A., 1985. 542 p.

RAIJ, B.V. Avaliação da fertilidade do solo. Piracicaba: Instituto Internacional da Potassa. 1981.142p.

SIMÃO, S. O abacaxizeiro. In: SIMÃO, S. Tratado de fruticultura. Piracicaba: FEALQ, p.249-288.1998.

VITTI, G.C. Acidez no solo, calagem e gessagem. In: Curso de Atualização em Fertilidade do Solo 1. Ilha Solteira-SP. 18 a 22/05/87. Campinas-SP: Fundação Cargill, 303-248p. 1987.

YAMADA, T.; ROBERTS, T.L. Potássio na agricultura brasileira. Piracicaba: Associação Brasileira da Potassa e do Fosfato, 2005. 841p. 